\title{
COMPETÊNCIAS, SOFRIMENTO E CONSTRUÇÃO DE SENTIDO NA ATIVIDADE DE AUXILIARES DE ENFERMAGEM EM UTIN
}

\author{
SKILLS, SUFFERING AND CONSTRUCTION OF MEANING IN THE ACTIVITY OF AUXILIARY \\ NURSES IN THE NEONATAL INTENSIVE CARE UNIT (NICU)
}

\author{
Luciana Gomes ${ }^{1}$ \\ Letícia Pessoa Masson $^{2}$ \\ Jussara Cruz de Brito ${ }^{3}$ \\ Milton Athayde ${ }^{4}$
}

Resumo $\mathrm{O}$ artigo trata das competências requeridas/ desenvolvidas nas atividades de auxiliares de enfermagem de uma Unidade de Terapia Intensiva Neonatal (Utin) em articulação com a saúde dessas trabalhadoras (o sofrimento $\rightarrow$ prazer no trabalho). A perspectiva da ergologia orienta o esforço investigativo, incorporando outros referenciais, como os contidos nos estudos de Zarifian e Dejours. No plano metodológico, ainda tendo o ponto de vista da atividade como operador sintético, foram feitos levantamento e análise de documentos e visitas à Utin, operando-se com o dispositivo Encontros sobre o Trabalho, da Comunidade Ampliada de Pesquisa (CAP). Concluiu-se que o coletivo de auxiliares, protagonista do trabalho em análise, construiu um patrimônio de conhecimentos práticos sobre o seu trabalho e uma base minimamente eficaz de transmissão desse patrimônio. Fazendo uso da abordagem 'Psicodinâmica do Trabalho', ressaltou-se o caráter desafiante que o trabalho em UTI Neonatal apresenta, o que envolve saber lidar não só com o sofrimento dos neonatos como também o de mães e familiares, inclusive como forma de defesa contra seu próprio sofrimento, evitando um rumo patogênico. Observou-se, por fim, que é premente a demanda de qualificação formal por parte dessas trabalhadoras, o que propiciaria, dentre outros importantes benefícios, um maior reconhecimento social, com efeitos positivos sobre sua própria saúde.

Palavras-chave trabalho em saúde; UTI Neonatal; sofrimento psíquico; ergologia; Psicodinâmica do Trabalho.
Abstract The article deals with vocational training and skills required in the activity of nursing staff in Neonatal Intensive Care Unit (NICU) in conjunction with the 'body-self' and the health of these workers. It discusses the issue of jurisdiction in synergy with other issues relevant to her, as the ratio of service and suffering $\rightarrow$ pleasure working. The perspective of Ergology guides the investigative effort, incorporating other materials such as Zarifian and Dejours. At the methodological level, even taking the viewpoint of activity as synthetic operator, made visits to the NICU, survey and analysis of documents and operated with the device Meetings on the Work of the Community Extended Search. It was concluded that this collective assistants built a heritage of practical knowledge about their work and a basis minimally effective transmission of this heritage. Using the approach of 'work labor psychodynamics', it was emphasized that the character challenging work in the NICU has, which also involves coping with the suffering of mothers and relatives of newborns, including as a defense against his own suffering, avoiding a pathogenic way. It was also highlighted the importance of the possibility of renormatization, recentering of the environment in which they work, the extent that their values can be expressed. It was observed, finally, that there is a pressing demand for formal qualifications by these workers, which would provide, among other important benefits, greater social recognition, with positives effects to the health.

Keywords health work; NICU; psychic suffering; ergology; work labor psychodynamics. 
A Unidade de Terapia Intensiva Neonatal (Utin) é um espaço reservado no hospital para tratamento de recém-nascidos prematuros, que necessitam de cuidados 24 horas por dia, e de bebês que apresentam algum tipo de problema ao nascer. Pelas próprias características desse tipo de usuário, como seu tamanho e maturidade, bem como pelos problemas - distintos das outras faixas etárias - que podem vir a apresentar, a estrutura física da Utin costuma ser diferente de outras UTIs e dispõe de metodologia e filosofia de atendimento diferenciados (Moreira, Bonfim e Llerena Júnior, 2006). É um ambiente sociotécnico complexo, repleto de aparelhos sofisticados.

Os enfermeiros e os profissionais de enfermagem de nível médio e/ou fundamental (técnicos e auxiliares) estão entre os profissionais que, junto aos médicos, formam a estrutura básica de uma equipe de cuidados intensivos neonatais. Revelando um forte corte de gênero (Brito, 2005), nesse tipo de unidade frequentemente a maioria de auxiliares e técnicos de enfermagem é formada por mulheres. São essas profissionais que convivem a maior parte do tempo com os bebês-usuários-pacientes e são responsáveis pelo seu cuidado direto.

O trabalho realizado por auxiliares de enfermagem tem sido considerado simples, quando comparado ao exercido por médicos e enfermeiros (Lopes e Leal, 2005; Gaíva e Scochi, 2004; Scochi et al., 1997; Rego, 1993). Entretanto, análises feitas a partir do 'ponto de vista da atividade' (Schwartz, 2000a; Brito, 2005), em que se busca considerar tudo o que envolve o trabalho situado, especialmente a sua realização - não só as tarefas como também as atividades desenvolvidas -, mostram a incontornável mobilização do 'corpo-si' (Schwartz, 2010b; Durrive e Schwartz, 2008) e as demais entidades coletivas relativamente pertinentes (ECRPs) ${ }^{5}$ (Schwartz, 2010c). Destaca-se a presença de um quadro de complexidade, sutileza e riqueza (Masson, 2007), assim como o uso de um significativo conhecimento técnico, sendo o profissional efetivamente responsável pelo que faz (Silva, 2006).

Pode-se afirmar que há uma falta de reconhecimento das qualificações e competências necessárias para desenvolver essas atividades, vistas como pertinentes a características femininas inatas. Entendemos que essa naturalização se deve, ao menos em parte, à associação feita desse trabalho com as atividades doméstico-maternais, além da própria história de construção da enfermagem, ligada à abnegação e submissão femininas ao hegemônico poder (médico) masculino. Agrega-se a isso o fato de que, em nosso sistema público de saúde, vem se tornando crônica uma perversa intensificação do trabalho, com rotinas cada vez mais complexas, contraditórias, com condições materiais e organizacionais precarizadas e número insuficiente de profissionais. Tal configuração parece exigir não apenas a mobilização de competências individuais, mas, especialmente, o desenvolvimento de novas competências coletivas, de ECRP. 
Neste artigo, apresentamos, exploramos e discutimos resultados de uma pesquisa que buscou "conhecer aspectos menos visíveis (e verbalizáveis) da atividade de trabalho de auxiliares de enfermagem ${ }^{6}$ de uma Unidade Neonatal e sua relação com a saúde destas trabalhadoras" (Masson, 2007, p. 8).

\section{Relação de serviço e competências mobilizadas no trabalho em saúde}

Entende-se que está em curso nas últimas décadas uma tendência para a crescente complexificação nas formas de trabalho e de atividade, exigindo novas atribuições e mobilizações - ao nível do corpo, da potencialidade cognitiva, afetiva e social - aos trabalhadores e trabalhadoras. Nas atividades em que se destaca uma 'relação de serviço' (Zarifian, 200la, 2001b), em especial no trabalho em saúde, a introdução de novas tecnologias, o aumento da complexidade da estrutura do sistema e as novas formas de gestão geram também, crescentemente, novas atribuições aos pacientes/usuários, relacionadas, especialmente, à coprodução do serviço. Nesse cenário, emergem novas questões, relacionadas à competência, à eficácia, à saúde e à qualidade do trabalho realizado.

Os conceitos de evento, comunicação e serviço são propostos por Zarifian (200la) para tratar da temática da competência. Evento diz respeito ao que ocorre de maneira parcialmente imprevista, indicando que "a competência profissional não pode mais ser enclausurada em definições prévias de tarefas a executar" (Zarifian, 2001a, p. 42). No tocante à comunicação, ela tornou-se um componente essencial do trabalho, pois a qualidade das interações e da intercompreensão é fundamental para melhorar o desempenho no trabalho. O conceito de serviço concerne ao trabalho contemporâneo, qualquer que seja o setor de atividade (não só o de seviços): “Trabalhar é gerar um serviço, ou seja, é uma modificação no estado ou nas condições de atividade de outro humano, ou de uma instituição, que chamaremos de destinatários do serviço (o cliente, no setor privado, o usuário, no setor público)" (Zarifian, 200la, p. 48, grifos do autor).

Ainda segundo esse autor, na chamada 'lógica de serviço', a qualidade é definida em função da maneira como um produto melhora qualitativamente as condições de produção ou de vida de um cliente/usuário. Assim, desenvolver uma competência no sentido da produção de serviço é "se perguntar sobre a maneira como o produto que se realiza beneficiará utilmente os destinatários" (Zarifian, 200lb, p. 145), ou seja, é estar realmente interessado na transformação positiva das condições de atividade dos destinatários do serviço.

Segundo Schwartz (2010a, p. 208), é difícil definir a noção de competência ajustada a uma situação de trabalho, uma vez que "os limites de 
uma situação de trabalho não são jamais descritíveis, eles são imprecisos". Da mesma forma, caso se tente detectar competências numa situação de trabalho, considerando certa atividade, também nos deparamos com algo sempre indefinível, na medida em que ela é sempre microrrecriadora, um 'encontro de encontros', de singularidades, de variabilidades a gerir. Portanto, na perspectiva ergológica,

a competência industriosa é uma combinatória problemática de ingredientes heterogêneos que não podem ser avaliados nos mesmos moldes, e muito menos ainda quando ela inclui uma dimensão de valor, uma vez que ninguém dispõe de uma escala absoluta de avaliação dos valores (Schwartz, 1998).

Em seu entendimento, existem diferentes elementos presentes na noção de competência e que não se articulam facilmente, pois se trata de dimensões da experiência humana de certa forma não comparáveis. Assim, ele prefere falar em 'agir em competência' e, para isso, é necessária a combinação, em diferentes medidas e proporções, de certo número desses elementos heterogêneos, que ele irá denominar 'ingredientes'7, como na culinária.

Já Du Tertre (2005) destaca que, atualmente, nas relações de serviço, as exigências em torno da qualidade e a intensificação do trabalho têm colocado novos desafios à saúde dos trabalhadores. Para o autor, o processo de arbitragem entre os objetivos fixados pela hierarquia, a especificidade da demanda do beneficiário (com sua presença corporal, com a dinâmica subjetiva daí emergente) e a própria representação que o trabalhador constrói de sua missão é o coração da dinâmica dos serviços, tendo consequências para a saúde dos trabalhadores.

Conforme Hubault (2009, p. 100), "na relação de serviço, com efeito, a saúde é antes de mais nada uma questão de eficácia, pois ela se coloca em termos de recurso disponível para agir". Nela se solicita um tipo de atividade em que a 'subjetividade' do agente é reconhecida como essencial, inspirando e supondo um modelo de eficácia renovada, particularmente na maneira de abordar a saúde. Segundo ele, as questões de saúde que a relação de serviço coloca podem se referir a dois níveis possíveis: à natureza singular dos recursos individuais e coletivos mobilizados ("o modo "particular' do engajamento da subjetividade na relação de serviço") e ao grau de reconhecimento presente em uma organização concreta ("o modo 'real' da organização da relação de serviço") (Hubault, 2009, p. 101). Nesse sentido, para o autor, o quadro de esgotamento dos trabalhadores pode tanto resultar dos esforços empregados para 'responder' à singularidade de cada cliente/usuário/paciente quanto da inexistência de soluções disponíveis para atender ao mesmo. 


\section{Abordagem teórico-metodológica}

A pesquisa teve como principais referências a concepção canguilhemiana de vida e saúde (Canguilhem, 2002), a perspectiva ergológica (Schwartz, 2000a; Brito, 2004) sobre atividade e trabalho e o enfoque da relação entre sofrimento psíquico e trabalho presente na abordagem Psicodinâmica do Trabalho (Dejours, 2008).

A partir de Canguilhem (2002), compreende-se que a saúde não se limita ou se identifica com a simples ausência de doença. Ela é entendida como potência para tolerar e compensar as 'infidelidades' do meio. Assim, mais do que prevenir os riscos, a saúde possibilita a abertura aos riscos através da capacidade de lidar com eles, transformando-os (ou seja, através da conquista dos meios para viver os riscos). Distinguindo-se das abordagens finalistas e mecanicistas da adaptação, ser saudável, para o autor, é ser mais do que adaptativo, é ter uma margem de tolerância não só para enfrentar, como também para superar as infidelidades do meio (Caponi, 1997; Nouroudine, 2004).

Nesta mesma linhagem, Schwartz (2002) afirma que toda vida humana para de se manifestar de forma sadia a partir do momento em que o meio pretende lhe impor integralmente as suas normas, tornando-se um meio 'invivível', o que é efetivamente impossível.

Embora entendamos haver diferenças com Canguilhem e Schwartz, pode-se aqui aproximar a concepção de saúde defendida por Dejours (1986, 1992), quando ele assinala que nunca é neutra a relação entre trabalho e saúde. Nesta relação, o trabalhar tem a potência de agir como um operador de saúde, podendo fortalecer a sua conquista ou contribuir para o adoecimento. Assim, a questão correta em relação à saúde não é 'trabalhar ou não trabalhar'; a questão bem colocada é: 'qual trabalho, para quê, para quem?'. Ou seja, diríamos no vocabulário daqueles autores: é na possibilidade de criar novas normas ('capacidade normativa', 'renormatização') de acordo com a situação e os próprios valores (individuais e coletivos), recriando o meio em que se vive e se trabalha, é recentrando-o mesmo que parcial e provisoriamente que se pode caminhar em direção ao ideal de saúde (à saúde, antes de mais nada, como valor).

Quanto ao modo de produção de conhecimento, na perspectiva ergológica, a cooperação entre profissionais das ciências e protagonistas da atividade é a condição para a construção e o desenvolvimento de conhecimentos mais fecundos e pertinentes à atividade e ao trabalho. Para que esta cooperação se efetive, Schwartz (1996, 2000a, 2000b), buscando desenvolver outros modelos já experimentados (seja pela ergonomia da atividade, pelo modelo operário italiano de luta pela saúde etc.), propõe um 'dispositivo dinâmico 
de três polos' (DD3P). Um paradigma que visa a colocar em debate sinérgico diferentes saberes, seja o que se tornou patrimônio das disciplinas científicas (primeiro polo), seja aqueles investidos pelos protagonistas em sua atividade (segundo polo). No magnetismo da relação entre essas forças, é imprescindível a atuação de um terceiro polo, operando acordos e negociações, considerando as exigências éticas/epistêmicas, incontornáveis para que se dê o encontro fecundo entre os diferentes saberes. Reitera-se a absoluta relevância desse terceiro polo no dispositivo, considerando que a complexidade da atividade e do trabalho configura zonas de cultura e incultura entre as partes, gerando desconforto intelectual recíproco e exigindo uma postura de humildade epistemológica.

Com essa inspiração no paradigma ergológico do DD3P, desde o final dos anos 1990 buscamos no Brasil agir com uma configuração desse dispositivo que denominamos Comunidade Ampliada de Pesquisa (CAP) (Brito e Athayde, 2003; Silva et al., 2009), destacando-se que aí circula uma comunidade dialógica (França, 2007). As indicações de Dejours no plano metodológico não estão aí presentes inteiramente, em especial quanto ao encaminhamento interpretativo nos 'encontros sobre o trabalho', como se denomina em ergologia (Durrive, 2010). Assim como na 'análise ergonômica do trabalho' (Guérin et al., 2001), também não nos furtarmos a apresentar indicações para mudanças ao coletivo ('caderno de encargos'), nem a eventualmente acompanhar sua implementação. O encaminhamento da pesquisa inicial que serviu de base para o artigo envolveu os seguintes procedimentos:

- Visitas à Unidade Neonatal (UN), 8 envolvendo observações e conversas com as trabalhadoras;

- Levantamento e análise de documentos relativos às normas antecedentes e às prescrições do trabalho (rotinas escritas do trabalho na UN, legislação do exercício profissional de enfermagem, relatórios, escala de serviço e planta física da unidade);

- Encontros sobre o Trabalho, com um coletivo de auxiliares, para discussão e análise das atividades de trabalho em relação à saúde;

- Validação final dos resultados junto ao coletivo de trabalho participante da coinvestigação.

Desde o início, conforme o dispositivo CAP, um dos objetivos foi a ampliação da 'comunidade' investigativa. O primeiro passo, tendo uma representação e compreensão inicial do hospital, foi a realização de dez visitas à UN, em diferentes plantões (inclusive noturno), quando se iniciou a aproximação das auxiliares de enfermagem e de suas atividades de trabalho, buscando também o melhor conhecimento do funcionamento daquela unidade específica. Durante essas visitas, foram realizadas observações do trabalho e das atividades e conversas dialógicas com as auxiliares de enfermagem, cujos conteúdos foram registrados em diário de campo imediatamente após 
sua execução. Nessa etapa, inspiramo-nos (também sem segui-la à risca) na análise ergonômica da atividade.

Para a realização da segunda etapa da pesquisa, de levantamento e análise de documentos, buscou-se conhecer o que a ergologia (na linhagem de Canguilhem) denomina 'normas antecedentes': todo um amplo conjunto do que é dado, exigido, apresentado ao trabalhador antes de o trabalho ser realizado. Esse conceito apreende em seu interior o que a ergonomia da atividade designa por tarefa, 'trabalho prescrito' (Brito, 2006), abarcando outros aspectos, tais como a historicidade e a origem da própria prescrição, os valores e um patrimônio conceitual, científico e cultural (Telles e Alvarez, 2004). Nesse sentido, Brito (2006, p. 284) entende que as normas antecedentes são:

vinculadas a aquisições da inteligência e experiência coletiva (e, neste sentido, bens de todos). Essas normas referem-se aos saberes técnicos, científicos e culturais que historicamente são incorporados ao fazer (como os diferentes saberes e técnicas do campo da saúde).

Após uma análise inicial dos materiais gerados nas duas primeiras etapas, operou-se com o dispositivo 'Encontros (da CAP) sobre o Trabalho' (no total de seis). Procurou-se dialogar sistematicamente com aquele coletivo de trabalhadoras a propósito de temas pertinentes ao seu trabalho, às atividades que desenvolvem, permitindo uma confrontação sinérgica entre os saberes científicos e saberes da prática, o que resultou em uma compreensão conjunta sobre aquela realidade de trabalho, considerando-se as características próprias de cada forma de processar o conhecimento.

Os encontros ocorreram dentro da jornada de trabalho, com a participação de nove auxiliares de um dos plantões (que possui vinte destas profissionais), que se revezavam entre as reuniões, gerando grupos de três a cinco participantes. Em cada encontro, com duração de cerca de uma hora, houve a apresentação de conceitos e análises, seguida da discussão de diferentes temas, colocando em foco as atividades de trabalho na UN e a saúde das trabalhadoras.

Segundo Durrive (2010), os Encontros sobre o Trabalho são cadinhos para o retrabalho dos saberes, conforme a dinâmica do DD3P. Nesse sentido, o 'animador' dos encontros deve procurar favorecer a dinâmica gerada pelo terceiro polo (ético-epistêmico) do dispositivo. Assim, após ressaltar a importância do ponto de vista da atividade e chamar a atenção para a sua complexidade, para os desafios e as mobilizações aí implicados, o animador deve estimular os participantes dos encontros a fazerem uma rigorosa verbalização daquilo que a atividade ensina ${ }^{9}$. O objetivo da dinâmica dos Encontros sobre o Trabalho é que os participantes se fortaleçam para convocar 
saberes formais e reconvocá-los/validá-los, alimentando incessantemente novas perspectivas para o debate.

Os encontros foram assim organizados: Pré-encontro - Apresentação e discussão dos temas dos encontros; Encontro I - Formação profissional; Encontro II - Coletivos de trabalho; Encontro III - Organização do trabalho; Encontro IV - Condições de trabalho; Encontro de fechamento dessa etapa.

A análise efetuada dos materiais produzidos nos Encontros sobre o Trabalho se deu fundamentalmente sobre a produção linguageira emergente nesses encontros, destacando a motricidade dialógica (Bakthin, 2003; França, 2007). Assim, os procedimentos de análise envolveram leitura exaustiva dos relatórios de observação dos encontros e das transcrições dos diálogos, visando a identificar que direções o diálogo percorreu e quais conexões estabeleceu. Com o objetivo de enriquecer a análise, recorreu-se também ao método da Psicodinâmica do Trabalho, no que tange ao interesse especial pelos comentários dos trabalhadores, sem contudo interpretá-los. Para Dejours (2008), poder dialogar com outrem é a forma mais potente de pensar a experiência vivida e, no caso do grupo, um meio de elaboração coletiva das experiências e ainda um 'operador de construção do próprio coletivo'.

A Psicodinâmica do Trabalho mostrou-se útil também para abordar a questão do sofrimento no trabalho e sua relação com a mobilização das competências. Dejours entende que o sofrimento é uma vivência primordial da relação do humano com o seu trabalhar. Mas esse sofrimento pode ser transformado em prazer, advindo do ganho obtido no trabalho justamente no registro da construção da identidade e da realização de si, por meio da dinâmica do reconhecimento: "Sem o reconhecimento, não pode haver sentido, nem prazer (...), só há sofrimento patogênico e estratégias defensivas, sem reconhecimento, haverá inevitavelmente desmobilização" (Dejours, 2008, p. 262).

Como última etapa da pesquisa, retornou-se ao hospital para validação dos resultados encontrados junto às auxiliares de enfermagem, em três novos Encontros sobre o Trabalho. Para propiciar uma melhor comunicação e, consequentemente, o debate entre saberes, os resultados foram apresentados sinteticamente em Power Point e em impressos ('cadernos') que foram distribuídos para as participantes.

Nesse processo de validação, foram privilegiados os seguintes temas: a formação profissional das auxiliares de enfermagem; as condições de trabalho das auxiliares de enfermagem; a organização do trabalho e a formação de coletivo de trabalho na atividade das auxiliares de enfermagem.

Em relação aos aspectos éticos, a pesquisa seguiu todas as exigências, tendo o projeto sido aprovado tanto pelo Comitê de Ética em Pesquisa da Escola Nacional de Saúde Pública Sergio Arouca (Ensp) quanto pela direção do hospital onde o trabalho de campo foi realizado. 


\section{Resultados e discussão}

O Serviço de Neonatologia, no qual o trabalho de campo foi realizado, pertence a um hospital público de grande porte, especializado no atendimento à saúde da mulher e referência na assistência à gestante de alto risco e na assistência integrada às mulheres vítimas de violência sexual, localizado em um bairro central do município do Rio de Janeiro. O serviço divide-se em: Unidade de Tratamento Intensivo (Utin), Unidade Intermediária (UI) e Unidade de Baixo Risco (UBR), também chamada de Berçário de Baixo Risco (BBR) ou Unidade Mãe-Bebê. Há ainda os setores de medicação e de material, nos quais o conjunto de profissionais de enfermagem (auxiliares e enfermeiros) atuam. O número de leitos para os neonatos naquele momento era de vinte na UTI, 24 na UI, dez na UBR e seis na Unidade Canguru para o 'binômio' mãe-bebê.

A equipe de auxiliares de enfermagem do Serviço de Neonatologia era formada por seis grupos de plantonistas: três diurnos e três noturnos, somando cerca de cem trabalhadores dessa categoria profissional, sendo a grande maioria $(99,4 \%)$ mulheres. Cada turno de trabalho de 12 horas contava com uma média de 18 auxiliares plantonistas, quatro enfermeiros plantonistas no turno diurno e três enfermeiros plantonistas no noturno. No que tange ao vínculo empregatício, 90\% das auxiliares eram servidoras públicas municipais. O restante das auxiliares (10\%) trabalhava em regime de RPA (modalidade de contrato temporário da prefeitura do Rio de Janeiro). Cabe destacar ainda que o setor funcionava em janeiro de 2006 com um déficit de 37 auxiliares de enfermagem (cerca de seis profissionais por plantão) em relação às próprias recomendações da Secretaria Municipal de Saúde (SMS) da prefeitura do Rio de Janeiro 10 sobre o dimensionamento de profissionais para a assistência de neonatos.

Em seguida, destacaremos outros aspectos vinculados à formação profissional das auxiliares de enfermagem da Utin, iniciando pelos aprendizados que se mostraram necessários ao desenvolvimento dessa prática.

\section{Os diferentes caminhos que levam à formação de uma auxiliar de enfermagem de UTI neonatal}

Os diálogos com as auxiliares nas visitas e nos encontros mostraram que a construção de seu ofício, para elas, requer a conquista de determinadas 'qualidades', que comporiam uma competência industriosa, das quais parecem se orgulhar. Assim, para se tornar de fato uma auxiliar de enfermagem de Utin, seriam fundamentais tanto o tempo de experiência quanto saber lidar com os imprevistos e a capacidade de criar alternativas frente às variabilidades 
que estão sempre presentes, de maneira ainda mais premente na relação de serviço. Aqui recorreu-se a Zarifian (2001c, p. 43): “(...) o grau de experiência dos assalariados não depende mais, primordialmente, da duração de sua permanência no posto de trabalho, mas da variedade dos eventos enfrentados e da qualidade da organização que permite examiná-los a fundo."

Assim, destaca uma das auxiliares:

Você pode trabalhar muito tempo dentro de uma situação e não ter, sabe, desenvoltura para agir em determinada situação.

Dessa forma, ela chama a atenção para a complexidade dos elementos da competênciall relativos à incorporação do histórico de uma situação de trabalho. Assim, entende-se que esse grupo de auxiliares tem um patrimônio construído de conhecimentos práticos sobre o seu trabalho e suas atividades e uma base minimamente eficaz - mesmo que não estruturada formalmente - de transmissão desses saberes.

No diálogo sobre quem escolheu, ou não, ir para a Unidade Neonatal - ao serem convocadas após concurso público -, ressaltaram que, implicitamente, para trabalhar nesse setor seria preciso ter determinadas qualidades/competências que elas 'possuem', mas que não é qualquer pessoa que 'tem'. Dessa forma, elas parecem valorizar o seu coletivo profissional e dimensionar a complexidade de sua atividade de trabalho:

Até porque, realmente, a pessoa não tem, não é nem perfil, porque eu sou uma pessoa muito determinada, entendeu? Eu sempre encarei os desafios que me surgem pela frente, então nem todo mundo tem essa coisa de encarar.

Tem aquele medo e continua com aquele medo.

O caráter desafiante que o trabalho em UTI neonatal apresenta, conforme citado antes, foi algo bastante comentado pelas auxiliares em diversos momentos. Entende-se que esse desafio diz respeito aos conhecimentos técnicos necessários à realização de procedimentos complexos e ao manejo de tecnologias atuais e às condições de trabalho insatisfatórias. Mas também ao aspecto relacional da atividade das auxiliares materializado pelo constante contato com o sofrimento (dos bebês, das mães e famílias e do seu próprio sofrimento) e a morte, presentes em todo o trabalho em saúde, e ainda mais intensificados em UTIs.

Ao longo do exercício de 'falar sobre o trabalho e trabalhar a fala' (Faïta, 2005, 2010), as auxiliares começaram a observar o lado 'sombrio' do fato de terem adquirido uma certa experiência e desenvoltura, que estão ligadas ao 'costume' frente às situações de sofrimento dos bebês e de seus familiares. 
Elas afirmaram que, para lidar com questões difíceis no trabalho, como a morte de crianças, seria preciso um aprendizado específico. Remeteram a um aprendizado - nem sempre com resultados apenas positivos - que envolveria a própria experiência do coletivo de trabalho em incorporar as vivências (individuais e coletivas) das trabalhadoras a um patrimônio de valores e normas sobre modos de lidar com os pacientes e com as consequências dessa relação para a saúde delas próprias. Pode-se entender, com Dejours (2008), que o que elas denominam 'costume' trata-se do desenvolvimento de estratégias coletivas de defesa frente ao risco e ao medo de tornarem-se vulneráveis diante do sofrimento dos bebês e/ou de mães e familiares.

Quando falaram sobre as mães dos bebês, demonstraram certo estranhamento, apesar de buscarem compreender a situação delas, como ficou evidenciado em diversos encontros. As auxiliares disseram que estranhavam o sofrimento das mães (percebido como associado à ignorância do quadro clínico e/ou não aceitação da situação crítica do filho), mesmo que em outros momentos da pesquisa tenham tentado se colocar no lugar delas. Elas e as mães ocupam posições muito diferentes, mas que são constantemente confrontadas: a auxiliar - que "sabe do sofrimento da criança" -, em decorrência de "ficar muito fria", "vê que não tem solução", "torce" para que a criança "pare de sofrer" e se vá. Já a mãe "quer o filho dela" de qualquer jeito, "reza" pela sobrevivência do filho e nega a possibilidade de perdê-lo.

Saber lidar com o sofrimento dos familiares do bebê revela-se como algo fundamental, pois, caso contrário, as auxiliares poderiam fragilizar seus sistemas defensivos para lidar com seu próprio sofrimento. De acordo com a Psicodinâmica do Trabalho (Dejours, 2003, 2008), se elas permitirem o estabelecimento de mecanismos de identificação e de empatia com os bebês e os familiares, não conseguirão realizar suas atividades, pois não poderão mais sustentar sua invulnerabilidade, nem afastar suas angústias diante do sofrimento gerado pelo contato com bebês que necessitam de cuidados especiais.

\section{"Tem de gostar": a importância de um meio de trabalho em consonância com os valores das trabalhadoras}

Ao perguntarmos às auxiliares o que seria necessário uma pessoa ter para realizar o seu trabalho da melhor forma possível, uma delas afirmou categoricamente:

Tem de gostar, eu acho... Não adianta você ter tudo na sua mão e não querer trabalhar ("eu não quero trabalhar com aquela criança"), nada vai sair. 
Esta fala ressalta a importância de os valores e desejos das pessoas no trabalho poderem ser expressos e terem a possibilidade de recentramento do meio - mesmo que parcial e infinitesimal - em que se trabalha, ou seja, fazer com que aquele trabalho torne-se delas, tenha a ver com elas.

Como destaca Hubault (2009), a relação de serviço requer atividades de trabalho em que a 'subjetividade' do trabalhador é essencial - atividades que exigem sua implicação e participação, supondo sua autonomia. Para realizar esse tipo de atividade, é necessário ter as condições e formas de organização de trabalho que ajudem a pensar, a se implicar, a se comprometer ("ter tudo na sua mão"), mas há também o engajamento da 'subjetividade' da auxiliar nesta relação.

Outra auxiliar complementa:

Eu acho que, para mim, além de querer, você precisa - eu, pelo menos - sempre se colocar no lugar do paciente. Apesar de eles serem bebezinhos e de a gente não estar lidando com adulto. Mas é preciso saber se colocar no lugar da mãe, da família, como gostaria que o seu paciente fosse tratado... Então, pensando assim, você vai procurar sempre fazer o melhor.

Esta auxiliar expressava a relação de serviço estabelecida com os bebês e suas famílias, como algo a ser acrescentado ao "querer", dito pela outra auxiliar ao falar do que é necessário para se realizar o trabalho delas. O serviço por ela prestado - no sentido da 'lógica de serviço' -, que envolve uma atenção às expectativas e demandas dos seus usuários-clientes-destinatários, se coloca através da fala dela pela expressão "fazer o melhor".

Outro ponto que elas trouxeram sobre a relação com os familiares dos bebês foi a falta de reconhecimento da importância do seu trabalho. As auxiliares os sinalizaram como atores importantes na dinâmica do reconhecimento de seu trabalho, o que Dejours (2008) entende como um processo intimamente ligado à saúde mental, à construção de sentido e à transformação do sofrimento em prazer. Segundo elas, os familiares não reconhecem a sua participação na recuperação dos bebês, reconhecimento este que, quando ocorre, seria na maioria das vezes referido exclusivamente aos médicos.

As auxiliares falam que não haveria uma 'valorização profissional' do trabalho delas pela hierarquia. Retomaram este seu incômodo ao chamar a atenção a respeito da falta de elogios, também por parte dos pais dos bebês. Comentaram também sobre o investimento mobilizado ao buscarem exercer o valor construído por esse coletivo, que envolveria "fazer o melhor". Para as auxiliares, elas não apenas "fazem" o melhor, mas "dão" o melhor de si, o que demonstra a forte dimensão presente das dramáticas de uso de si (Schwartz, 2010b) neste trabalho, contrapondo-se a uma simples ideia de execução 
ao agir no trabalho. Também pode-se perceber que elas sabem do valor que têm como operadoras da engrenagem que envolve os cuidados e o tratamento dos usuários-pacientes, mas que, apesar disso, não se sentem minimamente reconhecidas nesse processo.

Retomando Dejours (2008), a dinâmica do reconhecimento passa, em um dos momentos do processo (que exige a existência de espaço público interno, confiança, visibilidade), pela reconstrução rigorosa das diversas formas de julgamento sobre o trabalho realizado. Embora não revelem sentir que haja um reconhecimento adequado do seu trabalho por parte da hierarquia, das demais categorias profissionais e dos familiares dos pacientes, esse reconhecimento se dá entre os pares imediatos (atenção aqui para a ausência de reconhecimentos pelos demais membros da equipe de trabalho), o que nesta clínica do trabalho considera-se relevante para a saúde mental:

Quando o julgamento é proferido pelos pares, oferece em contrapartida da contribuição do sujeito para o conjunto da obra uma retribuição em termos de identidade. (...) o sujeito é reconhecido como possuindo todas as qualidades e saberfazer daqueles que formam o coletivo de trabalho, a equipe, ou a comunidade à qual pertence (Dejours, 2008, p. 209, grifo do autor).

Uma auxiliar chama a atenção sobre a dificuldade em se relacionar com mães que não agem como coprodutoras do serviço, limitando-se a fazer cobranças (até de forma agressiva) sobre a atuação das profissionais, independentemente de sua participação de forma 'conjugada' ("não vou querer uma conjugação com aquela mãe"), ou seja, de forma a 'agir junto' no trabalho com os bebês.

Porém, enquanto o 'não querer uma conjugação com a mãe' estaria apontando para uma (im)possível relação de coprodução do serviço, ao dizer que não vai ter "uma coisa tão afetiva naquela mãe", esta auxiliar parecia estar sinalizando o fato de que a mãe, na medida em que é vista como usuária/cliente, seria também passível de receber cuidados. Assim como ela própria já expressou ao falar "vou sempre fazer o melhor na criança" na realização do seu cuidado, o que sem dúvida envolve uma forte dimensão afetiva. Como aponta Du Tertre (2005), essa coprodução desdobrando-se entre os dois atores, mas de maneira assimétrica, teria uma incidência forte sobre a 'subjetividade' de cada tipo de ator e sua intersubjetividade, assim como um impacto importante sobre a qualidade dos efeitos úteis do serviço e sobre os meios mobilizados para obtê-lo. 


\section{A importância da qualificação formal (invisível no caso delas) para a qualidade do trabalho e para a valorização de um 'ofício' das auxiliares}

As auxiliares afirmaram que a dimensão prática é aprendida suficientemente bem no dia a dia de trabalho e nos estágios (que já mostram a realidade). Aparece também uma demanda por cursos, chamando a atenção sobre a importância de saberem o que estão fazendo, de não fazerem seu trabalho 'no automático'.

Percebeu-se, a partir do ponto de vista ergológico, que as auxiliares de enfermagem possuíam uma competência mais desenvolvida no âmbito da dimensão histórica e da experiência corporal no trabalho ('ingrediente 2'), mas apresentavam uma demanda por qualificação que lhes trouxesse maior compreensão da atividade que realizam, bem como reconhecimento social.

Assim, a sua demanda premente remete ao nível da qualificação formal, coincidentemente ou não, aquele que lhes daria maior reconhecimento social e valorização profissional ("o auxiliar é tão mal visto...") e que as deslocaria do nível 'baixo' na pirâmide hierárquica hospitalar e social.

As auxiliares mostraram buscar a valorização dos saberes (como o saber formal) e competências que são necessários para exercer a sua atividade, deixando claro que não seria qualquer pessoa que poderia estar ali, fazendo o seu trabalho: “(...) porque tem de ter, pelo menos, noções básicas do que é feito (...) e você só vai saber isso se você for auxiliar, se tiver estudado alguma coisa da área da saúde". Com esse discurso, percebe-se a necessidade e a importância do 'ingrediente 1 ' da competência, relativo à qualificação formal para o exercício dessa profissão.

É claro que, em se tratando de 'auxiliares', esse ingrediente não é socialmente valorizado como tão significativo para esse segmento da categoria de trabalhadores da saúde, sendo considerado legítimo o exercício da profissão a partir de uma formação escolar e profissional básica. No entanto, através de uma breve consulta à história recente da enfermagem, pode-se entender que tal fala faz parte da busca dessa profissão em se fazer reconhecida pelo seu caráter técnico-científico, pela profissionalização inclusive universitária do cuidar, tentando se distanciar do modelo vocacional (maternal-religioso) da enfermagem (Maranhão, 2004).

A busca desse segmento de profissionais de enfermagem pela melhora de sua qualificação é tão forte que chegou-se a encontrar algumas fazendo o curso universitário de enfermagem para entender melhor as ações que realizavam como auxiliares e técnicas, e não apenas para se tornarem 'enfermeiras'. 


\section{Considerações finais}

Pode-se observar ao longo desta pesquisa que as auxiliares de enfermagem mobilizavam intensamente competências relacionais nas situações concretas de trabalho e no curso de suas atividades, fazendo sua gestão na forma de dramáticas de uso de si. Se o aspecto relacional está presente em qualquer atividade humana, entretanto, no setor de serviços, em uma relação de serviço, ele toma uma dimensão mais evidente. No caso das auxiliares de enfermagem, que inevitavelmente estabelecem intenso e extenso contato e relação com as pessoas em situação de grande fragilidade (os recém-nascidos, mas também seus familiares), essa dimensão mostra-se fundamental para a compreensão da dinâmica trabalho-saúde que se opera nas suas situações de trabalho.

Para tentar atender à demanda dos bebês e de seus familiares, as auxiliares de enfermagem mobilizam fortemente recursos individuais e coletivos. Entendemos que, dessa forma, a dimensão relacional é um decisivo aspecto dessa atividade, atuando como operador de saúde (ou adoecimento, quando é fragilizada sua capacidade normativa). Hubault (2009) propõe, a fim de evitar um comprometimento da saúde, que uma condição de trabalho nas atividades de serviço é pensar - como assinala o autor, "trabalhar é pensar" (Hubault, 2001, p. 14) -, devendo-se conceber situações de trabalho que ao menos não bloqueiem esse processo que envolve também o implicar-se, assumindo responsabilidades relativas a cada situação de trabalho.

Enfim, dentre outras descobertas que fogem ao escopo deste artigo, percebeu-se que, com o aumento da complexidade das atividades de cuidado em função das inovações tecnológicas (novas formas de tratamento, procedimentos cada vez mais complexos), as auxiliares sinalizam também para inovações que são necessárias para a (re)construção desse segmento de ofício, como o desenvolvimento de competências que possibilitem ampliar a compreensão sobre a atividade (transformando-a) e que aumentem o seu reconhecimento social.

\section{Nota do Editor}

Este artigo é parte da pesquisa "Trabalho real em 'serviços' e promoção da saúde", financiada pela Fundação Carlos Chagas Filho de Amparo à Pesquisa do Estado do Rio de Janeiro, bem como parte da dissertação de mestrado de Letícia Pessoa Masson (“A Dimensão Relacional do Trabalho de Auxiliares 
de Enfermagem de uma Unidade Neonatal: uma análise do ponto de vista da atividade"), concluída em 2007 na Escola Nacional de Saúde Pública Sergio Arouca (Ensp), da Fundação Oswaldo Cruz (Fiocruz). O projeto da pesquisa foi aprovado tanto pelo Comitê de Ética em Pesquisa da Ensp (parecer n. 28/2006 do Comitê de Ética em Pesquisa da Ensp - CAAE: 00029.0.031.000-06) quanto pela direção do hospital onde o trabalho de campo foi realizado.

\section{Notas}

I Doutoranda em Saúde Pública pela Escola Nacional de Saúde Pública Sergio Arouca da Fundação Oswaldo Cruz (Ensp/Fiocruz), Rio de Janeiro, Brasil. <lugomes@gmail.com> Correspondência: Cesteh/Fiocruz, Rua Leopoldo Bulhões, 1.480, sala 3, Manguinhos, CEP 21041-210, Rio de Janeiro, RJ, Brasil.

2 Doutoranda em Psicologia Social pela Universidade do Estado do Rio de Janeiro (Uerj), Rio de Janeiro, Brasil. <leticiapessoa@yahoo.com.br>

3 Pesquisadora do Centro de Estudo da Saúde do Trabalhador e Ecologia Humana (Cesteh), da Escola Nacional de Saúde Pública Sergio Arouca, Fundação Oswaldo Cruz (Ensp/Fiocruz), Rio de Janeiro, Brasil. Doutora em Saúde Pública pela Ensp, com pós-doutorado em Ergologia pela Université d'Aix-en-Provence, França. <jussaradebrito@gmail.com>

4 Professor do Instituto de Psicologia da Universidade do Estado do Rio de Janeiro (Uerj), Rio de Janeiro, Brasil. Doutor em Engenharia de Produção/Ergonomia pela Coppe/Universidade Federal do Rio de Janeiro (UFRJ), com pós-doutorado em Ergologia pela Université d'Aix-en-Provence, França. <athayde.milton@gmail.com>

5 Fazemos uso de noções que Schwartz vem desenvolvendo com a ergologia. Para entender a entidade enigmática que designa a noção de 'corpo-si', ele nos lembra que "o trabalho não existe sem alguém que trabalha. É difícil nomear este sujeito porque isso subentenderia que ele se encontraria bem delimitado, definido. Ora, se a atividade é efectivamente conduzida por alguém em carne e osso - ela inscreve-se em funcionamentos neurosensitivos de tal forma complexos que não se consegue dar a volta - esta actividade tem, além disso, prolongamentos que ultrapassam a pessoa física. São solicitados e mesmo incorporados, inscritos no corpo: o social, o psíquico, o institucional, as normas e os valores [do contexto e retrabalhados], a relação às instalações e aos produtos, aos tempos, aos homens, aos níveis de racionalidade, etc." (Durrive e Schwartz, 2008, p. 24). Corpo-si como história, história como memória sedimentada (como instância de transformação em patrimônio), como matriz, energia produtora do inédito no trabalho (Schwartz, 2000a), Quanto às ECRPs, para Schwartz (2010c), elas são como uma "sinfonia sem maestro". Esse tipo de 'entidade' (dadas suas fronteiras invisíveis) coletiva (dado que aí transitam informações) não preexiste ao trabalhar, como se apresentam as equipes nos organogramas (que corresponderia ao que o autor designa 'registro l'). É em seu curso que elas se configuram, inscrevendo-se, transitando com seus contornos nunca inteiramente definidos (daí sua geometria 'relativamente pertinente') na complexidade histórica de qualquer trabalhar. Segundo Schwartz (2010c, p. 149), “as ECRP são um lugar de trânsito no duplo sentido, entre: de um lado o pólo dos 
debates e, sobretudo dos valores em discussão no plano do que chamamos globalmente 'político'; de outro lado, o pólo no qual esses valores globais são processados e reprocessados no campo ou no território das atividades de trabalho, a um nível mais local".

6 Neste artigo, utilizaremos a denominação 'auxiliares de enfermagem' para indicar os profissionais contratados nesta função no hospital estudado, seja com a formação de nível fundamental ou nível médio. Entretanto, verificamos que na prática, em relação à formação profissional, este grupo é formado por auxiliares de enfermagem (que corresponde ao profissional de enfermagem de nível fundamental), técnicos de enfermagem (que corresponde ao profissional de enfermagem de nível médio) e até mesmo por profissionais com nível superior, seja na área de enfermagem ou não.

7 Para Schwartz (2010a), é preferível pensar que as competências são compostas por seis tipos de ingredientes heterogêneos: 1) "relativo domínio dos protocolos em uma situação de trabalho" (p. 209); 2) "relativa incorporação do histórico de uma situação de trabalho" (p. 210); 3) "capacidade de articular a face protocolar e a face singular de dada situação de trabalho" (p. 212); 4) "debate de valores ligado ao debate de normas, as impostas e as instituídas na atividade" (p. 215); 5) “a ativação ou a duplicação do potencial da pessoa, com suas incidências em cada ingrediente" (p. 219 ); 6) "tirar partido das sinergias de competências, em situação de trabalho" (p. 221).

8 Denominaremos aqui UN o setor de neonatologia do hospital em questão, o qual envolve, além da UTI em si, a UI (Unidade Intermediária), a UBR (Unidade de Baixo Risco) e a Unidade Mãe-Canguru.

9 A questão linguageira é decisiva, pois na CAP circula uma comunidade dialógica. A respeito da questão linguageira, ver Schwartz (2010d) e Faïta (2010).

10 Resolução SMS 864, de 12 de abril de 2002.

11 Conforme a perspectiva ergológica (Schwartz, 2010a), corresponderia ao 'ingrediente $2^{\prime}$ da competência.

\section{Referências}

BAKHTIN, Mikhail. Estética da criação verbal. 4. ed. São Paulo: Martins Fontes, 2003.

BRITO, Jussara. Saúde do trabalhador: reflexões a partir da abordagem ergológica. In: FIGUEIREDO, Marcelo et al. (Orgs.). Labirintos do trabalho: interrogações e olhares sobre o trabalho vivo. Rio de Janeiro: DP\&A, 2004. p. 91-114.

Trabalho e saúde coletiva: o ponto de vista da atividade e das relações de gê- nero. Ciência e Saúde Coletiva, Rio de Janeiro, v. 10, p. 879-890, 2005.

Trabalho prescrito. In: ESCOLA POLITÉCNICA DE SAÚDE JOAQUIM VENÂNCIO. (Org.). Educação profissional em saúde. Rio de Janeiro: Editora Fiocruz, 2006. p. 282-288.

BRITO, Jussara; ATHAYDE, Milton. Trabalho, educação e saúde: o ponto de vista da atividade. Trabalho, Educação e Saúde, Rio de Janeiro, v. 1, n. 2, p. 239-265, 2003. 
CANGUILHEM, Georges. O normal e o patológico. Rio de Janeiro: Forense Universitária, 2002.

CAPONI, Sandra. Georges Canguilhem y el estatuto epistemológico del concepto de salud. História, Ciências, Saúde-Manguinhos, Rio de Janeiro, v. 4, n. 2, p. 287-307, 1997.

DEJOURS, Christophe. Por um novo conceito de saúde. Revista Brasileira de Saúde Ocupacional, São Paulo, v. 14, n. 54, p. 7-11, abr./maio/jun. 1986.

Normalidade, trabalho e cidadania.

Cadernos CRP, v. 6, p. 13-17, 1992.

. A loucura do trabalho. 5. ed. São Paulo: Cortez, 2003.

DURRIVE, Louis. Pistas para o ergoformador animar os Encontros sobre o Trabalho. In: SCHWARTZ, Yves; DURRIVE Louis. (Orgs.). Trabalho e ergologia: conversas sobre a atividade humana. 2. ed. revista e ampliada. Niterói: EdUFF, 2010. p. 309-318.

DURRIVE, Louis; SCHWARTZ, Yves. Glossário da ergologia. Laboreal, v. 4, n. 1, p. 23-28, 2008. Disponível em: <http://laboreal.up.pt/revista/ artigo.php?id=48u56oTV6582234396587; 63882>. Acesso em: 10 jan. 2011.

DU TERTRE, Christian. Services immatériels et relationnels: intensité du travail et santé.@ctivités, v. 2, n. 1, p. 37-49, 2005. Disponível em: <http://www.activites.org/ v2nl/dutertre.pdf $>$. Acesso em: 15 maio 2010.

FAÏTA, Daniel. Análise dialógica da atividade profissional. Rio de Janeiro: Imprinta Express, 2005.

A linguagem como atividade. In: SCHWARTZ, Yves; DURRIVE, Louis. (Orgs.). Trabalho e ergologia: conversas sobre a atividade humana. 2. ed. revista e ampliada. Niterói: EdUFF, 2010. p. 165-186.

FRANÇA, Maristela. Uma comunidade dialógica de pesquisa: atividade e discurso em guichê hospitalar. São Paulo: Fapesp/Educ, 2007.
GAÍVA, Maria Aparecida; SCOCHI, Carmem. Processo de trabalho em saúde e enfermagem em UTI neonatal. Revista Latino-Americana de Enfermagem, Ribeirão Preto, v. 12, n. 3, p. 469-476, 2004.

GUÉRIN, François et al. Compreender o trabalho para transformá-lo: a prática da ergonomia. São Paulo: Edgard Blücher, 2001.

HUBAULT, François. Faire de l'ergonomie une pensée... In: (Org.). Comprendre que Travailler c'est Penser, um Enjeu Industriel de l'Intervention Ergonomique. Toulouse: Octarès, 2001. p. 11-31.

L'approche ergonomique des questions santé/travail. Mouvements, n. 58, p. 97 102, 2009/2. Disponível em: <www.cairn. info/article.php?ID_REVUE=MOUV\&ID_ NUMPUBLIE $=$ MOUV_058\&ID_ARTICLE= MOUV_058_0097>. Acesso em: 12 dez. 2010.

LANCHMAN, Selma; SZNELWAR, Laerte I. (Orgs.) Christophe Dejours: da psicopatologia à psicodinâmica do trabalho. Rio de Janeiro, Brasília: Editora Fiocruz, Paralelo 15, 2008.

LOPES, Marta Júlia; LEAL, Sandra Maria. A feminização persistente na qualificação profissional da enfermagem brasileira. Cadernos Pagu, Campinas, v. 24, p. 105-125, 2005.

MARANHÃO, Rosa Maria. Reforma psiquiátrica: novas cartografias de trabalho para os técnicos e auxiliares de enfermagem psiquiátrica. Tese de doutorado, Rio de Janeiro: Pontifícia Universidade Católica, 2004.

MASSON, Letícia. A dimensão relacional do trabalho de auxiliares de enfermagem de uma unidade neonatal: uma análise do ponto de vista da atividade. Dissertação de Mestrado, Rio de Janeiro: Escola Nacional de Saúde Pública, Fundação Oswaldo Cruz, 2007.

MOREIRA, Maria Elisabeth; BOMFIM, Olga Luiza; LLERENA JÚNIOR, Juan. Esperando um bebê de risco. In: MOREIRA, Maria Elisabeth; BRAGA, Nina; MORSCH, Denise. (Orgs.). Quando a vida começa diferente: 
o bebê e sua família na UTI neonatal. Rio de Janeiro: Editora Fiocruz, 2006. p. 107-116.

NOUROUDINE, Abdallah. Risco e atividades humanas: acerca da possível positividade aí presente. In: FIGUEIREDO, Marcelo et al. (Orgs.). Labirintos do trabalho: interrogações e olhares sobre o trabalho vivo. Rio de Janeiro: DP\&A, 2004. p. 37-62.

REGO, Marisa. Trabalho hospitalar e saúde mental: o caso de um hospital geral e público no município do Rio de Janeiro. Dissertação de Mestrado, Rio de Janeiro: Instituto de Medicina Social, Universidade do Estado do Rio de Janeiro, 1993.

SCHWARTZ, Yves. Ergonomie, philosophie et exterritorialité. In: DANIELLOU, François. (Org.). L'Ergonomie en Quête de ses Principes: débats épistémologiques. Toulouse: Octarès, 1996. p. 141-182.

Os ingredientes da competência: Um exercício necessário para uma questão insolúvel. Educação \& Sociedade, Campinas, v. 19, n. 65, dez. 1998. Disponível em: $<$ www.scielo.br/scielo.php?script=sci_artt ext\&pid=S0101-73301998000400004\&lng= pt\&nrm=iso >. Acesso em: 1 mar. 2010.

. Le Paradigme Ergologique ou un Métier de Philosophe. Toulouse: Octarès, 2000a.

A comunidade científica ampliada e o regime de produção de saberes. Trabalho \& Educação, Belo Horizonte, n. 7, p. 38-46, 2000b.

A abordagem do trabalho reconfigura nossa relação com os saberes acadêmicos: as antecipações do trabalho. In: SOUZA-E-SILVA, Maria Cecília; FAÏTA, Daniel (Orgs.). Linguagem e trabalho: construções de objetos de análise no Brasil e na França. São Paulo: Cortez, 2002. p. 109-126.

Uso de si e competência. In: SCHWARTZ, Yves; DURRIVE, Louis. (Orgs.). Trabalho e ergologia: conversas sobre a atividade humana. 2. ed. revista e ampliada. Niterói: EdUFF, 2010a. p. 205-221.
Trabalho e uso de si. In: SCHWARTZ, Yves; DURRIVE, Louis. (Orgs.). Trabalho e ergologia: conversas sobre a atividade humana. 2. ed. revista e ampliada. Niterói: EdUFF, 2010b. p. 191-204.

A dimensão coletiva do trabalho: as "ECRP". In: SCHWARTZ, Yves; DURRIVE, Louis. (Orgs.). Trabalho e ergologia: conversas sobre a atividade humana. 2. ed. revista e ampliada. Niterói: EdUFF, 2010c. p. 149-164.

A linguagem em trabalho. In: SCHWARTZ, Yves; DURRIVE, Louis. (Orgs.) Trabalho e ergologia: conversas sobre a atividade humana. 2. ed. revista e ampliada. Niterói: EdUFF, 2010d. p. 131-148.

SCOCHI, Carmem et al. A organização do trabalho na assistência ao recém-nascido em berçários da regional de Ribeirão Preto - SP. Brasil - 1992. Revista Latino-Americana de Enfermagem, Ribeirão Preto, v. 5, n. 1, p. 2736, 1997.

SILVA, Cláudia O. Trabalho no hospital: ritmos frenéticos, rotinas entediantes. Cadernos de Psicologia Social do Trabalho, v. 9, n. 1, p. 15-32, 2006.

SILVA, Edil Ferreira et al. A promoção da saúde a partir das situações de trabalho: considerações referenciadas em uma experiência com trabalhadores de escolas públicas. Interface - Comunicação, Saúde e Educação, Botucatu, v. 13, p. 107-119, 2009.

TELLES, Ana Luiza; ALVAREZ, Denise. Interfaces ergonomia-ergologia: uma discussão sobre trabalho prescrito e normas antecedentes. In: FIGUEIREDO, Marcelo et al. (Orgs.). Labirintos do Trabalho: interrogações sobre o trabalho vivo. Rio de Janeiro: DP\&A, 2004. p. 63-90.

ZARIFIAN, Philippe. Mutação dos sistemas produtivos e competências profissionais: a produção industrial de serviço. In: SALERNO, Mario Sérgio. (Org.). Relação de serviço: produção e avaliação. São Paulo: Senac, 2001a. p. 67-94. 
. Valor, organização e competência na produção de serviço: esboço de um modelo de produção de serviço. In: SALERNO, Mario Sérgio. (Org.). Relação de Serviço: produção e avaliação. São Paulo: Senac, 2001 b. p. 95-150.

Objetivo competência: por uma nova lógica. São Paulo: Atlas, 2001c.

Recebido em 18/01/2011

Aprovado em 18/02/2011 